\title{
A Prática do Handebol na Cultura Físico-Esportiva de Escolares do Rio de Janeiro
}

\author{
Nadia Lima da Silva* \\ Marcos Santos Ferreira** \\ Vanessa Cerqueira Pasko*** \\ Helder Guerra de Resende ${ }^{* * * *}$
}

\begin{abstract}
Resumo: Este estudo decorre do mapeamento da cultura físico-esportiva de uma amostra representativa de estudantes matriculados no último ano do ensino fundamental das escolas da rede municipal do Rio de Janeiro, cujo objetivo foi verificar o nível de adesão à prática do handebol nas aulas de Educação Física e no lazer. O handebol é a terceira atividade físicoesportiva mais praticada na escola pelos estudantes, sobretudo do grupo feminino. Essa popularidade, ao mesmo tempo em que está aquém do sugerido por especialistas e dirigentes esportivos, faz do handebol uma atividade tipicamente escolar, dada sua reduzida prática nos espaços e tempos não escolares.
\end{abstract}

Palavras-chave: ensino fundamental; educação física; handebol.

\section{INTRODUÇÃo}

O handebol, como jogado atualmente, começou a ser difundido no Brasil a partir de 1950 por Auguste Listello, que preconizava ser esta uma das modalidades esportivas coletivas de fácil aprendizagem

\footnotetext{
'Professora Adjunto do Departamento de Esportes Individuais do Instituto de Educação Física e Desportos - UERJ; Professora Adjunto - 20 horas - do Departamento de Fundamentos da Educação Física da Faculdade de Educação Física e Desportos - UFJF - e-mail: nadialima@globo.com

"Universidade do Estado do Rio de Janeiro - UERJ; Universidade Gama Filho - UGF -e-mail: msantosferreira@uol.com.br

".*Professora de Educação Física do Ensino Fundamental - SME - E-mail: vanessapasko@yahoo.com.br

-...VVice-Reitor de Pós-Graduação, Pesquisa e Extensão - UCB; Professor Adjunto - 20 horas - do Departamento de Fundamentos da Educação Física da Faculdade de Educação Física e Desportos - UFJF - e-mail: heldergr@globo.com
} 
que, portanto, deveria ser ensinada nas aulas de Educação Física (SILVA, 1995). O handebol foi incluído no Campeonato Escolar de São Paulo de 1954 e, em 1971, nos Jogos Estudantis Brasileiros (JEB's) (SILVA, 1995). Para Peixe (1999), a realização desses eventos foi decisiva para o desenvolvimento da modalidade.

No Rio de Janeiro, o handebol foi inicialmente adotado nas escolas para, depois, alcançar os clubes, sendo considerado, ainda hoje, um esporte quase que essencialmente escolar (SILVA, 1995), ao contrário do ocorrido com o voleibol e o basquetebol, que foram desenvolvidos primeiramente em clubes e associações.

Comumente ouve-se de professores de Educação Física que o handebol é o esporte coletivo mais fácil de ensinar e de aprender, por reunir movimentos básicos como corrida, salto e arremesso. Sua simplicidade permite que o iniciante domine em pouco tempo a dinâmica funcional do jogo, constituindo-se em um meio acessível para a educação do movimento, da sua percepção e da relação entre os indivíduos (SHIGUNOV, PEREIRA, 1993).

No entanto, verifica-se um conflito entre as opiniões circulantes nos meios da Educação Física e do esporte em geral. Professores de Educação Física relatam que o handebol é a modalidade esportiva mais fácil e aprazível de ser ensinada e aprendida (PASKO, 2005), além de ser a modalidade esportiva com o maior número de inscrições nos jogos estudantis (PEIXE, 1999). Por outro lado, a mídia carioca ora enaltece o handebol como esporte mais popular nas escolas, ora reclama de sua pouca massificação nesse ambiente, opinião compartilhada por dirigentes esportivos e especialistas desse esporte (PASKO, 2005).

Diante dessa divergência, questiona-se em que posição aparece o handebol entre as atividades físico-esportivas praticadas na escola e fora dela. Sendo assim, este estudo teve por objetivo mapear a cultura físico-esportiva de estudantes do último ano do ensino fundamental das escolas públicas municipais do Rio de Janeiro, para verificar a posição ocupada pelo handebol nas aulas de Educação Física e nos horários fora da escola. 


\section{Considerações Metodológicas}

Foi realizado um estudo descritivo, do tipo 'survey'. Os sujeitos investigados são jovens matriculados no $9^{\circ}$ ano das escolas públicas da rede municipal do Rio de Janeiro. Nesta etapa escolar, os estudantes, via de regra, já tiveram oito anos de prática de diferentes atividades físico-esportivas nas aulas de Educação Física. Portanto, são capazes de fornecer dados sobre suas experiências e preferências físico-esportivas no contexto escolar e não escolar.

A amostra do estudo foi estabelecida a partir da probabilidade de sucesso fixada em 0,5 , considerando um intervalo de confiança de $5 \%$. A população de estudantes do $9^{\circ}$ ano do ensino fundamental na época da coleta dos dados era de 47.214 jovens. A amostra foi calculada por meio da técnica de amostragem estratificada simplificada, computando-se um quantitativo de 394 sujeitos distribuídos por 30 escolas de todas as regiões do município, obtendose uma média de 13 estudantes por unidade escolar.

Utilizou-se um questionário para a coleta de dados especificamente desenvolvido para esta pesquisa. O questionário foi submetido à avaliação qualitativa de cinco especialistas, para verificar a clareza das perguntas e das opções de resposta, bem como a adequação e a consistência das perguntas em função dos objetivos e questões da pesquisa. O índice de reprodutibilidade do questionário, testado por meio da correlação não paramétrica de Spearman, mostrou-se superior a $0,80 \mathrm{em}$ mais de $90 \%$ das questões.

Para a aplicação do questionário foram cumpridas todas as exigências éticas acadêmicas, bem como as normas da Secretaria Municipal de Educação, que recebeu, avaliou e aprovou o projeto da pesquisa. Os responsáveis pela direção de cada escola aquiesceram o trabalho proposto, assim como os responsáveis pelos estudantes menores de idade assinaram o termo de consentimento pósinformado. 
Os dados obtidos foram analisados com base nos percentuais das respostas assinaladas. O uso da estatística descritiva, ainda que tenha limitações inferenciais, mostrou-se adequada para a análise dos resultados.

\section{Apresentaçãoe Discussão dos Resultados}

Das 30 escolas envolvidas na pesquisa, vinte e duas $(73,3 \%)$ dispõem de instalações básicas, ou seja, um espaço cimentado em dimensões reduzidas sem, necessariamente, ter as linhas demarcatórias dos esportes de quadra; sete $(23,3 \%)$ possuem quadras polivalentes cobertas, com as demarcações e medidas semelhantes às oficiais; e uma $(3,4 \%)$ possui espaço improvisado (pátio cimentado sem as características de uma quadra) para a realização das aulas de Educação Física.

O questionário foi preenchido por 394 estudantes, sendo 200 meninas $(50,8 \%)$ e 194 meninos $(49,2 \%)$. A idade média dos estudantes é de 15,3 anos, variando de 13 a 18 anos para o grupo feminino e de 13 a 22 para o masculino.

A discussão dos dados está organizada em duas seções. A primeira se refere às práticas físico-esportivas extraescolares dos estudantes e a segunda seção aborda as atividades escolares mais praticadas e preferidas pelo grupo. Buscou-se verificar se os dados diferiam em relação aos gêneros, ressaltando-se somente os casos em que foi possível observar diferenças marcantes.

3.1 Experiências e motivações para prática de atividades físicoesportivas no espaço não escolar

A partir de tópicos gerais, chegou-se às questões que revelam as atividades físico-esportivas praticadas fora da escola, verificandose com que incidência o handebol aparece como opção de prática por parte do grupo investigado.

Com a primeira questão - "O quanto você gosta de praticar atividades físico-esportivas?" - procurou-se detectar se os estudantes gostam de praticar atividades físico-esportivas (Tabela 1). 


\begin{tabular}{|c|c|c|}
\hline Nível de gosto & $\mathbf{n}$ & $\%$ \\
\hline Adoro & 151 & 38,3 \\
\hline Gosto & 191 & 48,5 \\
\hline Indiferente & 31 & 7,9 \\
\hline Não gosto & 18 & 4,6 \\
\hline Odeio & 03 & 0,7 \\
\hline TOTAL & 394 & 100 \\
\hline
\end{tabular}

Os dados revelam que a maioria dos estudantes gosta ou adora praticar atividades físico-esportivas $(86,8 \%)$. Apenas $13,2 \%$ da amostra revelou um sentimento indiferente ou desfavorável ao referido tipo de prática.

Esses resultados reforçam as evidências trazidas por outros estudos de que os adolescentes sentem-se atraídos por atividades físico-esportivas pelo gosto. Pimenta (2007) investigando a população de adolescentes estudantes da cidade do Rio de Janeiro também encontrou o gosto pela atividade físico-esportiva como o principal motivo para a adesão à sua prática. Do mesmo modo, Monteiro et al. (2003) revelaram que o principal motivo apontado por 11.033 sujeitos do norte e nordeste do Brasil para a prática da atividade física foi a recreação (97,5\% dos homens e 85,3\% das mulheres), índice fortemente influenciado pelo tipo de atividade praticada: esportes. Castro et al. (2009) confirmam esses achados ao identificarem o gosto como o segundo maior motivo que levou indivíduos entre 15 e 20 anos a se inserirem em práticas físicoesportivas no SESC do Distrito Federal.

No entanto, o gosto pela prática de atividades físico-esportivas não implica, necessariamente, em adesão à prática regular deste tipo de atividade. Portanto, pareceu ser oportuno verificar a frequência da prática de atividades físico-esportivas por parte dos estudantes envolvidos nesta pesquisa, dado levantado através da seguinte questão: "Fora da escola, com que freqüência você pratica atividades físico-esportivas?" (Tabela 2). 
Tabela 2 - Frequência da prática de atividades físico-esportivas fora da escola

\begin{tabular}{lcccc}
\hline \multicolumn{1}{c}{ Frequência } & n & $\mathbf{\%}$ & $\begin{array}{c}\text { Masc } \\
\mathbf{\%}\end{array}$ & $\begin{array}{c}\text { Fem } \\
\mathbf{\%}\end{array}$ \\
\hline De vez em quando & 226 & 57,4 & 40,3 & 59,7 \\
Sempre & 141 & 35,8 & 67,8 & 32,2 \\
Nunca & 25 & 6,3 & 24 & 76 \\
Sempre, porque sou obrigado & 2 & 0,5 & 50 & 50 \\
\hline TOTAL & $\mathbf{3 9 4}$ & $\mathbf{1 0 0}$ \\
\hline
\end{tabular}

Os dados revelam que não há correspondência direta entre a dimensão de estudantes que gostam ou adoram praticar atividades físico-esportivas $(86,8 \%)$ e a dimensão daqueles que praticam frequentemente as atividades em pauta (36,3\%). Esses dados contradizem os apontados por Pimenta (2007), que revelaram correspondência entre os percentuais de adolescentes que dizem gostar de atividades físico-esportivas e os que realmente as praticam. A diferença encontrada pode dever-se ao fato de que Pimenta (2007) investigou alunos do último ano do ensino fundamental de escolas públicas e privadas, enquanto este envolveu apenas alunos de escolas públicas. A diferença encontrada por Pimenta (2007) pode ser decorrente da maior oportunidade de acesso à prática de atividades físico-esportivas por parte dos alunos das escolas privadas, cujo nível sócio-econômico é maior, tendência também corroborada por Gomes, Siqueira e Sichieri. (2001), Oehlschlaeger et al. (2004), Castro et al. (2009; 2010) e Palma et al. (2006).

Constataram-se diferenças entre a adesão de alunas e alunos à prática de atividades físico-esportivas nos tempos e espaços nãoescolares (Tabela 2). Do grupo de 226 estudantes que declararam praticar atividades físico-esportivas 'de vez em quando', 59,7\% é constituído por meninas, enquanto $40,3 \%$ por meninos. Tal relação é invertida quando se refere à opção 'sempre'. Dos 143 estudantes que praticam atividades físico-esportivas frequentemente, a proporção de meninos $(67,8 \%)$ é bem maior do que a de meninas $(32,2 \%)$. Por último, dentre os 25 que nunca praticam atividades físico-esportivas, a proporção de alunas (76\%) é cerca de três vezes 
maior do que a de alunos (24\%). Os meninos praticam atividades físico-esportivas com mais regularidade quando comparados com as meninas da mesma faixa etária.

Estudos populacionais realizados em países desenvolvidos (MANIOS; KAFATOS; CODRINGTON, 1999; CASPERSEN; PEREIRA; CURRAN, 2000) e no Brasil (GOMES; SIQUEIRA; SICHIERI, 2001, SALLES-COSTA et al., 2003) também revelam a predominância da prática de atividades físico-esportivas entre os homens. Quando se leva em consideração o gasto calórico despendido por homens e mulheres a partir da realização de atividades físicas em geral e físico-esportivas, os resultados não são diferentes quando comparados com os encontrados neste estudo. Em geral, os homens são mais ativos que as mulheres (SILVA et al., 2007, SOUZA; DUARTE, 2005; GUEDES et al., 2001, SILVA; MALINA, 2000).

Considerando que 25 sujeitos informaram não praticar atividades físico-esportivas fora do ambiente escolar (Tabela 2), a Tabela 3 expõe os principais motivos indicados pelos demais 369 sujeitos, que responderam à pergunta "Por que você pratica atividades físicoesportivas fora da escola?"

Tabela 3 - Motivos para a prática de atividades físico-esportivas fora do ambiente escolar

\begin{tabular}{lccccccc} 
& \multicolumn{1}{c}{ Motivos } & n & \% & \multicolumn{3}{c}{ Masculino } & \multicolumn{2}{c}{ Feminino } \\
\cline { 5 - 8 } & & & & n & \% & n & \% \\
\hline Simplesmente gosto & 76 & 20,6 & 41 & 21,2 & 35 & 19,3 \\
Melhor opção para ocupar meu tempo livre & 68 & 18,4 & 42 & 21,8 & 26 & 14,4 \\
Melhorar meu preparo físico & 45 & 12,2 & 29 & 15 & - & - \\
Quero ter um corpo bonito & 42 & 11,4 & - & - & 34 & 18,8 \\
Quero ser ou sou um atleta & 34 & 9,2 & 25 & 13 & - & - \\
Outros motivos & 100 & 27,1 & 50 & 24,4 & 83 & 45,8 \\
Sem resposta & 4 & 1,1 & 1 & 4,6 & 3 & 1,7 \\
\hline TOTAL & $\mathbf{3 6 9}$ & $\mathbf{1 0 0}$ & & & & \\
\hline
\end{tabular}

Os principais motivos indicados para justificar a prática de atividades físico-esportivas fora da escola são 'Porque simplesmente gosto' (20,6\%), 'Melhor opção para ocupar meu tempo livre' (18,4\%), 'Melhorar meu preparo físico' (12,2\%), e 'Quero ter um corpo bonito' $(11,4 \%)$. Os dois motivos mais apontados pela amostra referem-se ao gosto (39\%), enquanto os outros dois (condicionamento físico e corpo bonito) referem-se a intenções utilitárias $(23,6 \%)$. 
Segundo Lovisolo (1995, p. 213),

[a]s pessoas acreditam que fazem coisas ou agem porque (a) seguem uma norma (lei, regra, regulamentação, hábito ou costume), (b) pretendem alcançar algum objetivo ou finalidade utilitária e (c) gostam ou derivam algum prazer daquilo que fazem.

É interessante destacar, porém, que os motivos diferem entre gêneros. Entre os principais motivos apresentados pelo grupo feminino, dois referem-se ao prazer $(33,7 \%)$ - gosto pela prática de atividades físico-esportivas $(19,3 \%)$ e melhor opção disponível para ocupar o tempo livre $(14,4 \%)$ - e um à estética - desejo de obter um corpo bonito $(18,8 \%)$. Esses resultados alinham-se parcialmente aos obtidos por outros autores, que argumentam que a prática de atividades físico-esportivas no universo feminino associa-se à valorização dos cuidados com a imagem corporal (LINS, 1999) e à busca do corpo delineado e ao controle do peso corporal, fenômeno observado, sobretudo, em sociedades mais desenvolvidas (SALLESCOSTA, et al., 2003).

Já entre os principais motivos apresentados pelo grupo masculino, dois relacionam-se ao prazer (43\%) - melhor opção para ocupar meu tempo livre $(21,8 \%)$ e Simplesmente porque gosto $(21,2 \%)$ - e dois ao desempenho físico (28\%) - desejo de melhorar o condicionamento físico (15\%) e de se tornar um atleta (13\%). Esses resultados vão ao encontro dos de Castro (2010) que, ao investigar os principais motivos de adesão a programas de atividades físicoesportivas desenvolvidos pelos centros de atividades do SESC-DF, identificou que, enquanto o bem estar pessoal e a diversão foram apontados como motivação por ambos os grupos (masculino e feminino), a estética corporal não apareceu entre os principais motivos para o sexo masculino.

Ao responderem a questão "Qual a principal atividade físicoesportiva que você pratica ou praticou fora da escola?", os estudantes apontaram a preferência pelo 'futebol de campo' (24\%), 'futsal' (19\%) e 'dança' (10,8\%) (Tabela 4). 
Tabela 4 - Atividades físico-esportivas praticadas fora da escola

\begin{tabular}{lcccccc}
\hline \multirow{2}{*}{ Atividades } & n & \% & \multicolumn{3}{c}{ Masculino } & \multicolumn{2}{c}{ Feminino } \\
\cline { 5 - 8 } & & & $\mathbf{n}$ & $\mathbf{\%}$ & $\mathbf{n}$ & $\mathbf{\%}$ \\
\hline Futebol de Campo & 91 & 24,7 & 71 & 37,8 & 20 & 11 \\
Futsal & 70 & 19,0 & 60 & 31,9 & - & - \\
Dança & 40 & 10,8 & - & - & 37 & 20,4 \\
Jogos Recreativos & 35 & 9,5 & - & - & 32 & 17,7 \\
Natação & 34 & 9,2 & - & - & 21 & 11,6 \\
Voleibol & 21 & 5,7 & - & - & - & - \\
Handebol & 16 & 4,3 & - & - & - & - \\
Outras & 57 & 15,4 & 54 & 28,7 & 69 & 38,2 \\
Sem Resposta & 5 & 1,4 & 3 & 1,6 & 2 & 1,1 \\
\hline TOTAL & $\mathbf{3 6 9}$ & $\mathbf{1 0 0}$ & & & & \\
\hline
\end{tabular}

Considerando o foco central desta pesquisa, os dados indicam que poucos são os estudantes que praticam handebol fora da escola (apenas 16 ou 4,3\%). Entre os esportes coletivos, o handebol só aparece à frente do basquetebol que, na Tabela 4, integrou o item 'outras'.

A dança aparece entre as três atividades mais praticadas devido à boa adesão do grupo feminino. Trinta e sete meninas praticam dança fora da escola $(20,4 \%)$. Além da dança, os 'jogos recreativos' $(17,7 \%)$, a 'natação' $(11,6 \%)$ e o 'futebol de campo' (11\%) destacamse entre as meninas. $\mathrm{O}$ 'handebol' aparece apenas como a sexta atividade mais praticada pelas meninas $(8,3 \%)$ que, na Tabela 4 , integrou o item 'outras' que diz respeito a ambos os grupos.

O 'futebol de campo' $(37,8 \%)$ e o 'futsal' $(31,9 \%)$ são destacadamente as atividades mais praticadas pelos meninos fora da escola $(69,7 \%)$, enquanto que o handebol é praticado por apenas um aluno.

Os resultados sobre a predominância da prática do futebol e futsal entre os indivíduos do grupo masculino e a dança entre o do grupo feminino vai ao encontro dos achados de outros autores. Para Salles-Costa et al. (2003), os homens se engajam mais em atividades 
físicas coletivas de caráter competitivo, principalmente o futebol, e as mulheres em atividades individuais, que requerem do corpo menos força física, como a dança. Essa tendência também foi encontrada por Teixeira e Myotin (2001) para as práticas realizadas durante o recreio escolar. Em relação ao handebol, estes dados contrariam a representação que atletas e ex-atletas têm acerca da atribuição de gênero sobre as modalidades esportivas. Segundo Capitanio (2005), o handebol é visto como uma atividade tradicionalmente masculina no meio esportivo.

Cabe destacar, ainda, que para uma análise mais aprofundada do processo de adesão a práticas físico-esportivas fora da escola deve-se considerar na realização de outros estudos sobre o tema a existência, a distribuição e a acessibilidade a espaços e equipamentos físico-esportivos, dentre outros fatores.

Por que você não pratica ou pratica apenas de vez em quando atividades físico-esportivas fora da escola? Entre os estudantes que responderam essa questão (Tabela 2), 20,3\% indica a preguiça entre os principais motivos. De um lado, temos um grupo ávido pela prática de atividades físico-esportivas e, de outro, um quantitativo, de semelhante dimensão, autodefinido como 'preguiçoso'. Esses dois motivos não se diferenciam por gênero (Tabela 5).

Tabela 5 - Motivos para não praticar regularmente atividades físicoesportivas fora da escola

\begin{tabular}{lcc}
\hline \multicolumn{1}{c}{ Motivos } & n & $\mathbf{\%}$ \\
\hline Gosto de variar as atividades que faço & 56 & 22,3 \\
Sou preguiçoso & 51 & 20,3 \\
Não tenho condições econômicas & 37 & 14,7 \\
Realizo outras atividades mais importantes & 28 & 11,2 \\
Não tenho alguém para me acompanhar até o local & 21 & 8,4 \\
Tenho problemas de saúde & 12 & 4,8 \\
Prefiro fazer outras atividades mais legais & 6 & 2,4 \\
Minha religião não permite & 2 & 0,8 \\
Eu não gosto & 1 & 0,4 \\
Sem resposta & 37 & 14,7 \\
\hline TOTAL & $\mathbf{2 5 1}$ & $\mathbf{1 0 0}$ \\
\hline
\end{tabular}


O principal motivo apontado é a necessidade de variação da situação estímulo (22,3\%). A falta de condições econômicas $(14,7 \%)$ e a necessidade de realização de outras tarefas importantes fora do horário escolar $(11,2 \%)$ também são indicadas como motivos para que os jovens não pratiquem regularmente atividades físicoesportivas. Destaca-se, também, o fato de $11,8 \%$ das alunas não fazerem atividades físico-esportivas fora da escola por não disporem de companhia para levá-las ao local de prática. Como a amostra do presente estudo compreende jovens entre 13 e 22 anos, vale ressaltar que estudos indicam que, pelas circunstâncias socioculturais impostas aos adolescentes, estes tendem a substituir atividades físico-esportivas por maior quantidade de horas de estudo, incluindo cursos extras de inglês e informática, de convívio social com amigos, além da necessidade de entrada no mercado de trabalho (RAUDSEPP, VIIRA, 2000; SALLIS et al. 1992; DOUTHITT, 1994), o que justifica os motivos 'falta de condições econômicas' e a 'necessidade de realização de outras tarefas importantes fora do horário escolar' representarem, juntos, os principais motivos para a inatividade física desses jovens $(25,9 \%)$. Cabe destacar que, considerando a realidade da amostra investigada, a entrada no mercado de trabalho talvez seja o principal fator para justificar a inatividade física desses jovens. Nesse sentido, cabe destacar que levantamentos realizados pelo Instituto Brasileiro de Geografia e Estatística têm indicado que jovens de baixa renda tendem a entrar no mercado de trabalho a partir dos 10 anos de idade, com uma incidência maior dos 15 aos 24 anos, faixa etária que engloba a do presente estudo (IBGE, 2011a; 2011b; 2011c).

3.2 Experiências e motivações para a prática no contexto das aulas de educação física

Sobre a participação dos estudantes nas aulas de Educação Física, a proposição - "Assinale TODAS as atividades físicoesportivas que você pratica ou já praticou nas aulas de Educação Física na escola" - tratou das atividades físico-esportivas praticadas pelo menos uma vez ao longo dos oito anos de ensino fundamental nas aulas de Educação Física (Tabela 6). 
Tabela 6: Atividades físico-esportivas praticadas nas aulas de Educação Física

\begin{tabular}{lcccccc}
\hline \multirow{2}{*}{\multicolumn{1}{c}{ Atividades }} & \multirow{n}{*}{} & $\mathbf{0}$ & \multicolumn{3}{c}{ Masculino } & \multicolumn{2}{c}{ Feminino } \\
\cline { 5 - 8 } & & & $\mathbf{n}$ & $\mathbf{\%}$ & $\mathbf{n}$ & $\mathbf{\%}$ \\
\hline Voleibol & 297 & 75,4 & 138 & 71,1 & 159 & 79,5 \\
Futsal & 279 & 70,8 & 179 & 92,3 & 100 & 50,0 \\
Handebol & 277 & 70,3 & 115 & 59,3 & 162 & 81,0 \\
Jogos Recreativos & 230 & 58,4 & 69 & 35,6 & 161 & 80,5 \\
Basquetebol & 206 & 52,3 & 110 & 56,7 & 96 & 48,0 \\
Tênis de Mesa & 109 & 27,7 & 72 & 37,1 & 37 & 18,5 \\
Futebol de Campo & 90 & 22,8 & 45 & 23,2 & 45 & 22,5 \\
Dança & 70 & 17,8 & - & - & 58 & 29,0 \\
Ginástica & 64 & 16,2 & - & - & 52 & 26,0 \\
Atletismo & 51 & 12,9 & 32 & 16,5 & - & - \\
Outras & 82 & 20,7 & 62 & 32,0 & 63 & 31,5 \\
\hline
\end{tabular}

As atividades físico-esportivas praticadas nas aulas de Educação Física por mais de $50 \%$ da amostra foram: o 'voleibol' (75,4\%), o 'futsal' (70,8\%), o 'handebol' (70,3\%), os 'jogos recreativos' $(58,4 \%)$ e o 'basquetebol' $(52,3 \%)$. O handebol aparece como a terceira atividade mais praticada nas aulas de Educação Física da rede pública municipal do Rio de Janeiro, pouco diferindo das duas primeiras atividades mais praticadas. Entretanto, o mesmo não pode ser dito em relação aos jogos recreativos que, em quarto lugar, foram praticados por um número bem menor de estudantes $(58,4 \%)$. Esse resultado pode justificar o fato de a Secretaria Municipal de Educação do Rio de Janeiro apontar o handebol e o voleibol como os esportes com maior número de escolas inscritas nos jogos estudantis. O futsal, na década de 1990, não integrava o rol de esportes dos jogos estudantis do Rio de Janeiro, o que pode explicar o fato de ser uma atividade físico-esportiva entre as mais praticadas nas aulas de Educação Física, sem, no entanto, aparecer entre as modalidades com maior número de inscrições nos referidos jogos (PEIXE, 1999).

Estes resultados se diferem quando se compara as atividades mais praticadas por meninas e meninos (Tabela 6). $\mathrm{O}$ handebol é o mais praticado pelas alunas $(81 \%)$, seguido pelos jogos recreativos $(80,5 \%)$, pelo voleibol $(79,5 \%)$ e pelo futsal $(50 \%)$. Vale ressaltar 
que a dança $(29 \%)$ e a ginástica (26\%) apresentaram índices de prática inferiores ao do futsal $(50 \%)$ e muito próximos ao do futebol de campo $(22,5 \%)$.

Em relação ao grupo masculino, o futsal $(92,3 \%)$, o voleibol $(71,1 \%)$, o handebol $(59,3 \%)$ e o basquetebol $(56,7 \%)$ foram as atividades praticadas por mais da metade deste grupo ao longo do ensino fundamental.

Comparativamente, os jogos recreativos representam as atividades de diferenciação entre meninos e meninas, praticados por somente $35,6 \%$ dos meninos contra $80,5 \%$ das meninas. $\mathrm{O}$ mesmo ocorre em relação à dança - praticada por $29 \%$ do grupo feminino e por $6,2 \%$ do masculino - e com o handebol que, em terceiro lugar, é praticado por $81 \%$ do grupo feminino contra $59 \%$ do grupo masculino.

A frequência de prática de atividades físico-esportivas ensinadas nas aulas de Educação Física foi levantada através da seguinte questão: Assinale no máximo 3 atividades físico-esportivas que você PRATICOU COM MAIS FREQÜÊNCIA nas aulas de Educação Física na escola (Tabela 7). O suporte da questão orientava os alunos a colocar o número 1 ao lado da atividade praticada com maior freqüência; o número 2 para a segunda mais praticada; e o número 3 para a terceira atividade mais praticada nas aulas de Educação Física. Porém, para trabalhar numa perspectiva comparativa, computou-se a pontuação inversa à conferida pelos alunos na resposta ao questionário. Ou seja, as atividades assinaladas com o número 1 equivaleram a três pontos; as indicadas com o número 2 , a dois pontos; e as assinaladas com o número 3, a um ponto. Portanto, a pontuação indicada na Tabela 7 representa a soma de pontos obtidos por cada atividade físico-esportiva. Se todos os sujeitos envolvidos no estudo tivessem indicado a mesma atividade físico-esportiva como a mais praticada, esta atividade obteria um total de 1.182 pontos. 
Tabela 7: Atividades físico-esportivas mais praticadas na Educação Física escolar

\begin{tabular}{|c|c|c|c|c|c|c|}
\hline \multirow{2}{*}{ Atividades } & \multirow{2}{*}{ Pontos } & \multirow{2}{*}{$\%$} & \multicolumn{2}{|c|}{ Masculino } & \multicolumn{2}{|c|}{ Feminino } \\
\hline & & & Pontos & $\%$ & Pontos & $\%$ \\
\hline Futsal & 569 & 25,5 & 432 & 40,3 & 137 & 11,8 \\
\hline Handebol & 427 & 19,1 & 154 & 14,3 & 273 & 23,5 \\
\hline Voleibol & 421 & 18,8 & 195 & 18,2 & 226 & 19,5 \\
\hline Jogos Recreativos & 283 & 12,7 & - & - & 261 & 22,5 \\
\hline Basquetebol & 243 & 10,9 & 124 & 11,5 & 119 & 10,2 \\
\hline Futebol de Campo & 105 & 4,7 & 63 & 5,9 & - & - \\
\hline Tênis de Mesa & 55 & 2,5 & - & - & - & - \\
\hline Ginástica & 40 & 1,8 & - & - & - & - \\
\hline Dança & 31 & 1,4 & - & - & - & - \\
\hline Atletismo & 28 & 1,2 & - & - & - & - \\
\hline Natação & 18 & 0,8 & - & - & - & - \\
\hline Capoeira & 7 & 0,3 & - & - & - & - \\
\hline Folclore & 4 & 0,2 & - & - & - & - \\
\hline Tênis de Campo & 3 & 0,1 & - & - & - & - \\
\hline Outras & - & - & 105 & 9,8 & 145 & 12,5 \\
\hline TOTAL & 2.234 & 100 & 1073 & 100 & 1161 & 100 \\
\hline
\end{tabular}

O futsal $(25,5 \%)$, o handebol $(19,1 \%)$ e o voleibol $(18,8 \%)$ são apontados como as atividades físico-esportivas mais frequentemente praticadas nas aulas de Educação Física.

Entre as meninas, as atividades físico-esportivas mais praticadas são o handebol $(23,5 \%)$, os jogos recreativos $(22,5 \%)$, o voleibol $(19,5 \%)$, o futsal $(11,8 \%)$ e o basquetebol $(10,2 \%)$, enquanto que entre os meninos a destacadamente mais praticada é o futsal $(40,3 \%)$, seguida pelo voleibol $(18,2 \%)$, handebol $(14,3 \%)$, basquetebol $(11,5 \%)$ e futebol de campo $(5,9 \%)$ (Tabela 7$)$.

O resultado diferente encontrado entre meninos e meninas é surpreendente, uma vez que ao longo dos anos de 1980 as orientações curriculares vieram, gradativamente, superando a cultura de constituição das turmas de Educação Física separadas por sexo. Portanto, era de se esperar que os conteúdos das aulas fossem os mesmos. Esses resultados sugerem que os professores de Educação Física continuam diferenciando o conteúdo de ensino-aprendizagem por sexo, independentemente das turmas serem mistas ou não.

Algumas possibilidades podem ser apontadas para explicar este quadro. Dentre elas, chama atenção o fato de alguns estudos 
revelarem que é expressiva a dimensão de professores que negociam com os alunos as atividades a serem trabalhadas nas aulas de Educação Física (DARIDO, SANCHES NETO, 2005). Ao agirem assim, os professores dão margem a opções orientadas pelo que é mais prazeroso de se fazer (RESENDE, 1994). É possível também que o handebol seja uma opção preferencial de muitos professores, que podem considerá-lo mais fácil de ensinar, proporcionando aos alunos melhor domínio de suas habilidades motoras específicas.

Para investigar o gosto dos alunos por tais atividades, solicitouse que "Assinale NO MÁXIMO as 3 atividades físico-esportivas que MAIS GOSTOU DE PRATICAR nas aulas de Educação Física". Para análise, adotou-se a lógica de pontuação usada na questão anterior.

As meninas, por ordem de preferência, indicaram o handebol $(21,6 \%)$, o voleibol $(20,5 \%)$, os jogos recreativos $(19,8 \%)$ e o futsal $(12,6 \%)$, enquanto que os meninos elegeram o futsal $(40,5 \%)$, o voleibol $(16,7 \%)$, o basquetebol $(12,8 \%)$ e o handebol (12\%) (Tabela 8).

Tabela 8: Atividades físico-esportivas preferidas na Educação Física escolar

\begin{tabular}{lcccccc}
\hline \multirow{2}{*}{ Atividades } & \multirow{2}{*}{ Pontos } & \multirow{2}{*}{$\%$} & \multicolumn{2}{c}{ Masculino } & \multicolumn{2}{c}{ Feminino } \\
\cline { 5 - 8 } & & & Pontos & $\mathbf{\%}$ & Pontos & $\mathbf{\%}$ \\
\hline Futsal & 563 & 26,0 & 420 & 40,5 & 143 & 12,6 \\
Voleibol & 406 & 18,7 & 173 & 16,7 & 233 & 20,5 \\
Handebol & 369 & 17,0 & 124 & 12,0 & 245 & 21,6 \\
Jogos Recreativos & 249 & 11,5 & - & - & 224 & 19,8 \\
Basquetebol & 231 & 10,7 & 133 & 12,8 & 98 & 8,7 \\
Futebol de Campo & 126 & 5,8 & 69 & 6,7 & 57 & 5,0 \\
Tênis de Mesa & 72 & 3,3 & 53 & 5,1 & - & - \\
Dança & 43 & 2,0 & - & - & - & - \\
Ginástica & 40 & 1,8 & - & - & - & - \\
Atletismo & 24 & 1,1 & - & - & - & - \\
Natação & 20 & 0,9 & - & - & - & - \\
Folclore & 11 & 0,5 & - & - & - & - \\
Capoeira & 9 & 0,4 & - & - & - & - \\
Tênis de Campo & 7 & 0,3 & - & - & - & - \\
Outras & - & - & 64 & 6,2 & 134 & 11,8 \\
\hline TOTAL & $\mathbf{2 . 1 7 0}$ & $\mathbf{1 0 0}$ & $\mathbf{1 0 3 6}$ & $\mathbf{1 0 0}$ & $\mathbf{1 1 3 4}$ & $\mathbf{1 0 0}$ \\
\hline
\end{tabular}


Tanto as meninas quanto os meninos indicaram o handebol, o voleibol e o futsal entre as atividades mais preferidas, enquanto a diferenciação está no gosto das meninas pelos jogos recreativos e dos meninos pelo basquetebol. Vale ressaltar que o handebol figura em primeiro lugar na preferência das meninas e em quarto na dos meninos, com uma diferença marcante. Resultado inverso foi encontrado para o futsal.

Teixeira e Myotin (2001) encontraram resultados semelhantes em estudo realizado com escolares. $81 \%$ das meninas demonstraram interesse pelo handebol, enquanto que $96 \%$ dos meninos pelo futebol. Com relação ao handebol, objeto central deste estudo, chama atenção o fato de que as mulheres elegeram o handebol como a modalidade esportiva preferida nas aulas de Educação Física, embora não o praticassem fora da escola.

Boa parte dos meninos só atribuiu pontuação para o futsal, o que justifica o alto índice percentual conferido a esta unidade temática. A respeito dos jogos recreativos, pode-se afirmar que se trata de uma atividade muito apreciada pelas meninas, uma vez que sua indicação entre os meninos foi irrelevante, figurando percentualmente na Tabela 8 entre as outras modalidades. Enquanto para as meninas o handebol é a unidade temática preferida nas aulas de Educação Física, para os meninos ele aparece na quarta posição.

Mais uma vez, esses resultados reforçam os de Salles-Costa et al. (2003) e de Teixeira e Myotin (2001) quanto à preferência do grupo masculino pelo futebol/futsal. Para Salles-Costa et al. (2003), o futebol é a modalidade mais praticada entre os homens, provavelmente por ser um esporte incentivado desde a infância entre os meninos brasileiros.

No grupo feminino existe uma correspondência entre as unidades temáticas mais praticadas e aquelas que despertam maior gosto pela sua prática. Chama atenção a boa aceitação do futsal e do futebol de campo por parte das meninas. $\mathrm{O}$ gosto pela prática do futebol tem aumentado entre o grupo feminino, na medida em que o índice de 17,6\% dos pontos possíveis (somando-se o futsal e o futebol) 
constitui-se num indicador expressivo do gosto por esta atividade. Chama atenção, no entanto, que algumas atividades tidas como tipicamente femininas (dança e ginástica) não registraram índices de preferência relevantes, aparecendo percentualmente entre as outras atividades (Tabela 8). Os resultados de Teixeira e Myotin (2001) reforçam a idéia de que o gosto feminino pelo futebol vem aumentando, na medida em que esta modalidade esportiva foi apontada pelas garotas como a segunda de maior interesse (69\%). Supõem ainda que este interesse pode ter surgido a partir do momento em que as meninas tiveram a oportunidade de vivenciar a aprendizagem dessa modalidade esportiva nas aulas de Educação Física.

\section{Considerações Finas}

Os resultados sugerem que o handebol é uma atividade físicoesportiva típica da cultura escolar, praticada principalmente pelo grupo feminino. Portanto, o nível de popularidade do handebol nas aulas de Educação Física é decorrente, sobremaneira, da sua grande aceitação em termos de gosto e de prática entre o grupo feminino. Este resultado parece decorrer mais da opção pedagógica de ensinoaprendizagem dos professores de Educação Física do que da opção deliberada dos estudantes, pois a prevalência do gosto e da prática do handebol fora da escola não apresenta correspondência com o que ocorre nas aulas de Educação Física.

Pode-se inferir, portanto, que o handebol não é a atividade físicoesportiva mais popular e nem a mais praticada nas escolas investigadas, como afirmam especialistas da mídia, do handebol e dirigentes do esporte no Brasil ao se referirem à prática deste esporte nas escolas brasileiras. Por outro lado, pode-se afirmar que o handebol é uma atividade típica da cultura escolar, na medida em que é praticado fundamentalmente nas aulas de Educação Física, em contraste com a prática nos espaços e tempos não escolares. 
Handball practice in physical and sports culture of elementary school students in Rio de Janeiro Abstract: This study is based on the mapping of the physical and sports culture of a representative sample of public school students in their final elementary school year in Rio de Janeiro. The main goal of this study was to identify the levels of adherence to handball practice in both Physical Education classes and leisure time. Handball was found to be the third most practiced physical/sports activity among students, particularly girls. Although handball popularity was found to be lower than suggested by sports specialists and managers, it can be considered a typically school activity, given its reduced practice in non-school environments.

Keywords: elementary school; physical education; handball.

\section{La práctica del Balonmano en la Cultura Físico- Deportiva de Estudiantes Escolares de Rio de Janeiro \\ Resumen: Este estudio deriva del mapeo de la cultura} físico-deportiva de una muestra representativa de estudiantes inscriptos en el último año de la enseñanza fundamental de las escuelas de la red pública municipal de Rio de Janeiro. Su objetivo es verificar el nivel de adhesión a la práctica de dicho deporte en las clases de educación física y en los momentos de esparcimiento. El balonmano es el tercer actividad físico-deportiva más practicada por los estudiantes en la escuela, sobre todo el grupo femenino. Aunque el renombre del balonmano es más bajo que sugerido por los especialistas y los encargados de los deportes, este deporte puede ser considerado típicamente una actividad de la escuela, dada su práctica reducida en ambientes fuera de la escuela.

Palabras clave: enseñanza fundamental; educación física; balonmano. 


\section{REFERÊNCIAS}

CAPITANIO, A.M. Mulher, gênero e esporte: a análise da auto-percepção das desigualdades. 2005. Dissertação (Mestrado) - Escola de Educação Física e Esporte, USP, São Paulo, 2005.

CASPERSEN, C.J.; PEREIRA, M.A.; CURRAN, K.M. Changes in physical activity patterns in the United States, by sex and cross-sectional age. Medicine and Science in Sports and Exercise, Philadelphia, v.32, n. 9, p. 1601-1609, 2000.

CASTRO, M.S. et al. Motivos de Ingresso nos Programas de Exercícios Físicos Oferecidos pelo Serviço Social do Comércio - SESC-DF. Movimento, Porto Alegre, v. 15, n. 02, p. 87-102, abr./jun. 2009.

- Motivos de permanência dos praticantes nos programas de exercícios físicos oferecidos pelo Serviço Social do Comércio - Brasil. Motricidade, Santa Maria da Feira, v. 6, n. 4, p. 23-33, 2010.

DARIDO, S.C.; SANCHES NETO, L. O contexto da educação física na escola. In: DARIDO, S.C.; RANGEL, I.C.A. (Org.). Educação física na escola: implicações para a prática pedagógica. Rio de Janeiro: Guanabara Koogan, 2005. p. 2-24.

DOUTHITT, V.L. Psychological determinants of adolescent exercise adherence. Adolescence, Roslyn Heights, v.29, n.115, p.711-722, 1994.

GUEDES, D.P. et al. Níveis de prática de atividade física habitual em adolescentes. Revista Brasileira de Medicina do Esporte, Niterói, v. 7, n. 6, p. 187-199, 2001.

GOMES, V.B.; SIQUEIRA, K.S.; SICHIERI, R. Atividade física em uma amostra probabilística da população do Município do Rio de Janeiro. Cadernos de Saúde Pública, Rio de Janeiro, v. 17, n. 4, p. 969-976, 2001.

INSTITUTO BRASILEIRO DE GEOGRAFIAE ESTATÍSTICA- IBGE. O perfil da mulher jovem de 15 a 24 anos: características diferenciais e desafios. 2011a. Disponível em: <http://www.ibge.gov.br/home/estatistica/populacao/ populacao_jovem_brasil/ comentario2.pdf>. Acesso em: 13 JUL. 2011.

População de $\mathbf{1 0}$ anos ou mais de idade: taxas e desocupação. 2011b. Disponível em:<http://www.ibge.gov.br/home/estatistica/populacao/ mapa_mercado_trabalho/comentarios.pdf>. Acesso em: 13 JUL. 2011.

Projeção da População do Brasil. 2011c. Disponível em: <http:// ww w. ibge.gov.br/home/presidencia/noticias/ noticia_visualiza.php?id_noticia=1272>. Acesso em: 13 jul. 2011.

LINS, A.P.M. Fatores Associados ao sobrepeso em mulheres de 20 a 59 anos no Município do Rio de Janeiro. 1999. Dissertação (Mestrado) - Instituto Fernandes Figueira, Fundação Oswaldo Cruz, Rio de Janeiro, 1999. 
LOVISOLO, H. Normas, utilidades e gostos na educação. In: VOTRE S.J.; COSTA, V.L.M.C. (Org.). Cultura, atividade corporal e esporte. Rio de Janeiro: Editora Gama Filho, 1995. p. 213-231.

MANIOS, Y.; KAFATOS, A.; CODRINGTON, C. Gender differences in physical activity and physical fitness in young children in Crete. Journal of Sports Medicine and Physical Fitness, Torino, v.39, n.1, p. 24-30, 1999.

MONTEIRO, C.A. et al. A descriptive epidemiology of leisure-time physical activity in Brazil, 1996-1997. Revista Panamericana Salud Publica, Washington, v.14, n.4, p.246-254, 2003.

OEHLSCHLAEGER, M.H. Prevalência e fatores associados ao sedentarismo em adolescentes de área urbana. Revista de Saúde Pública, São Paulo, v. 38, n. 2, p. 157-163, 2004.

PALMA, A. et al. Dimensões epidemiológicas associativas entre indicadores socioeconômicos de vida e prática de exercícios. Revista Brasileira de Ciências do Esporte, Campinas, v. 27, n. 3, p. 119-136, 2006.

PASKO, V.C. A popularidade do handebol no contexto escolar e extraescolar do Rio de Janeiro. Dissertação (Mestrado).- Programa de Pós-Graduação em Educação Física, Universidade Gama Filho, Rio de Janeiro, 2005.

PEIXE, A.H.G. O incremento do Handebol como desporto educacional e de rendimento: problemas, expectativas e propostas. Dissertação (Mestrado) Departamento de Educação, Universidade Estácio de Sá, Rio de Janeiro, 1999.

PIMENTA, A.P.A.A. Prevalência da prática de atividades físico-esportivas extracurriculares e fatores associados entre adolescentes de 14 e 15 anos de idade, estudantes da oitava série do ensino fundamental no município do Rio de Janeiro. Dissertação. (Mestrado) - Programa de PósGraduação em Educação Física, Universidade Gama Filho, Rio de Janeiro, 2007.

RAUDSEPP, L.; VIIRA, R. Sociocultural correlates of activity in adolescents. Pediatric Exercise Science, Champaign, v.12, n.1, p.51-60, 2000.

RESENDE, H. G. Tendências pedagógicas da educação física escolar. In: RESENDE, H. G.; VOTRE, S. J. (Org.). Ensaios sobre educação física, esporte e lazer: tendências e perspectivas. Rio de Janeiro: Ed. Gama Filho/SBDEF, 1994. p.11-40.

SALLES-COSTA, R. et al. Gênero e prática de atividade física de lazer. Cadernos de Saúde Pública, Rio de Janeiro, v.19, suppl. 2, p. S325-S333, 2003.

SALLIS, J. F. et al. Determinants of physical activity and interventions in youth. Medicine and Science in Sports and Exercise, Philadelphia, v.24, suppl. 6, p.S248-257, 1992.

SHIGUNOV, V.; PEREIRA, V.R. Pedagogia da educação física. O desporto coletivo na escola. Os componentes afetivos. São Paulo: Ibrasa, 1993. 
SOUZA, G.S.; DUARTE, M.F.S. Estágios de mudança de comportamento relacionados à atividade física em adolescentes. Revista Brasileira de Medicina do Esporte, Niterói, v. 11, n. 2, p. 104-108, 2005.

SILVA, M. C. S. Difusão e cultura do handebol no Rio de Janeiro. Dissertação (Mestrado) - Escola de Educação Física e Desportos, Universidade Federal do Rio de Janeiro, Rio de Janeiro, 1995.

SILVA, R.C.R.; MALINA, R.M. Nível de atividade física em adolescentes do Município de Niterói, Rio de Janeiro, Brasil. Cadernos de Saúde Pública, Rio de Janeiro, v. 16, n. 4, p. 1091-1097, 2000.

SILVA, G.S.F. et al. Avaliação do nível de atividade física de estudantes de graduação das áreas saúde/biológica. Revista Brasileira de Medicina do Esporte, Niterói, v. 13 , n. 1, p. 39-42, 2007.

TEIXEIRA, A.G.A.; MYOTIN, E. Cultura corporal das meninas: análise sob a perspectiva de gênero. Motriz, Rio Claro, v. 7, n. 1, p. 45-48, 2001.

Endereço para correspondência

Helder Guerra de Resende

Avenida Santa Cruz, 1631 - Realengo

21710-250 - Rio de Janeiro - RJ.

Recebido em: 14.03.2011

Aprovado em: 13.12.2011

Vovimento, Porto Alegre, v. 17, n. 04, p. 123-143, out/dez de 2011. 
